\title{
Evolution and Application of a hysteretic loop correction Fatigue Model Da-Sheng Wei ${ }^{1, a^{*}}$, Kun $\mathrm{Li}^{1, \mathrm{~b}}$, Yan-Rong Wang ${ }^{1, \mathrm{c}}$ and Jing-yun $\mathrm{GAO}^{2, \mathrm{~d}}$ \\ ${ }^{1}$ School of Energy and Power Engineering, Beihang University, Beijing 100191, China \\ ${ }^{2}$ AVIC Commercial Aircraft Engine CO., LTD., Shanghai Engineering Research Center for Commercial Aircraft Engine, Shanghai 201108, China
}

adasheng.w@163.com, blikun_buaa@163.com, cyrwang@buaa.edu.cn, 'gaojingyun@acae.com.cn

Keywords: Low Cycle Fatigue, High Cycle Fatigue, Life Prediction, Fatigue-Creep Interaction, Powder Metallurgy

Abstract. A hysteretic loop correction (HLC) model was established by introducing the position and shape correction factors of hysteretic loop in early study (International Journal of Pressure Vessels and Piping, 86 (2009) 616-621) based on the testing data of two Ni-based super alloys of FGH95 and GH4169. This paper attempts to develop a general expression of the model to correlate the data of high-cycle fatigue, thermal-mechanical fatigue, and multi-axial fatigue. The form of the generalized hysteretic loop correction (GHLC) model is similar to the total strain equation just the coefficients are not constants but variables. The model shows more comprehensive applicability under different kinds of testing conditions and correspondingly applied to the life evaluation of a powder metallurgy (PM) disc of turbo engine. The results illustrate an agreement with linear damage accumulation model's calculation and design life of the disc.

\section{Introduction}

Potential risks and high maintain cost raised by fatigue are always a major concern in hot section structures of turbo engine. Investigation on fatigue behaviors and life evaluation of $\mathrm{Ni}$-based super alloys is the basis to meet the requirement of high reliability for aero engine structure in service. With the advancement of materials and the application of new structure, life prediction method has always been improved. The mechanics behaviors of advanced materials still should be explored and the corresponding life prediction methods are still far from perfection so far. Many studies on different types of materials have revealed the life prediction methods under fatigue, creep, and interaction conditions. In one important play called hot section technology (HOST) plan executed by NAS A (1980-1987), tests of isotropic, anisotropic, and protective coating materials were performed under isothermal and thermal-mechanical conditions. Based on these experiment data, many life models were established and validated in which some original models with good applicability are listed in Table 1.Most of these life equations can be classified as two groups: one is the Manson-Coffin equation and its modified forms, the other is strain range partitioning (SRP) model which leads to Strain Energy Partitioning (SEP) and total strain SRP (TSSRP) model.

Up to now, dozens of life models appear, and each life model is usually suitable for a particular material under some specific test conditions, so it brings the trouble to select the life models to predict the life of materials or structures. It is difficult to establish a general model but that is just an exploratory study in the paper. In fact, we develop the total strain forms of Manson-Coffin equation, and then try to find a more general form. 
Table 1 Life models for high temperature low cycle fatigue

\begin{tabular}{|c|c|c|c|c|}
\hline Type & No. & Method & Time & Founder \\
\hline \multirow{6}{*}{ Strain-based } & 1 & Manson-Coffin Equation[1,2] & $\begin{array}{l}1953, \\
1954\end{array}$ & $\begin{array}{l}\text { Manson, } \\
\text { Coffin }\end{array}$ \\
\hline & 2 & Frequency-Modified Model[3] & 1970 & Coffin \\
\hline & 3 & Frequency-Separation Model[4] & 1976 & Coffin \\
\hline & 4 & Damage Rate[5] & 1976 & Majumdar \\
\hline & 5 & Strain range-Partitioning Model[6] & 1971 & $\begin{array}{l}\text { Manson, } \\
\text { Halford }\end{array}$ \\
\hline & 6 & Total Strain SRP[7] & 1985 & Halford \\
\hline \multirow{3}{*}{ Energy-based } & 7 & Ostergren Model[8] & 1976 & Ostergren \\
\hline & 8 & Strain energy-Partitioning Model[9] & 1982 & Jin-Rui He \\
\hline & 9 & GFMDF Model[10] & 1994 & $\begin{array}{l}\text { Yong-Lian } \\
\text { Wang }\end{array}$ \\
\hline \multirow{3}{*}{ Damage-based } & 10 & $\begin{array}{l}\text { P-M Linear Damage Accumulation } \\
\text { Model[11] }\end{array}$ & $\begin{array}{l}1924, \\
1945\end{array}$ & $\begin{array}{l}\text { Palmgren, } \\
\text { Miner }\end{array}$ \\
\hline & 11 & $\begin{array}{l}\text { Cyclic Damage Accumulation } \\
\text { Model[12] }\end{array}$ & 1985 & P\&W Inc \\
\hline & 12 & $\begin{array}{l}\text { Chaboche Creep-fatigue Damage } \\
\text { Model[13] }\end{array}$ & 1990 & Chaboche \\
\hline
\end{tabular}

\section{Experiment and modeling}

\section{The HLC model}

Tests of two Ni-based superalloys, FGH95 and GH4169, were performed at $650^{\circ} \mathrm{C}$ under axial total strain control to investigate their fatigue behaviors. The strain rate was $5 \times 10^{-3} \mathrm{~s}^{-1}$, and the strain ratio was -1 . The strain ranges included $2 \%, 1.8 \%, 1.6 \%, 1.4 \%, 1.2 \%, 1.0 \%$ and $0.8 \%$. Four different types of loading were employed: strain cycling continuously (no dwell), strain cycling with 1 min hold at tensile peak, strain cycling with $1 \mathrm{~min}$ hold at compressive peak, and strain cycling with balanced $0.5 \mathrm{~min}$ hold both in tension and compression peaks [14]. The lives of the fatigue tests plotted as a function of the total strain range are shown in Fig. 1.

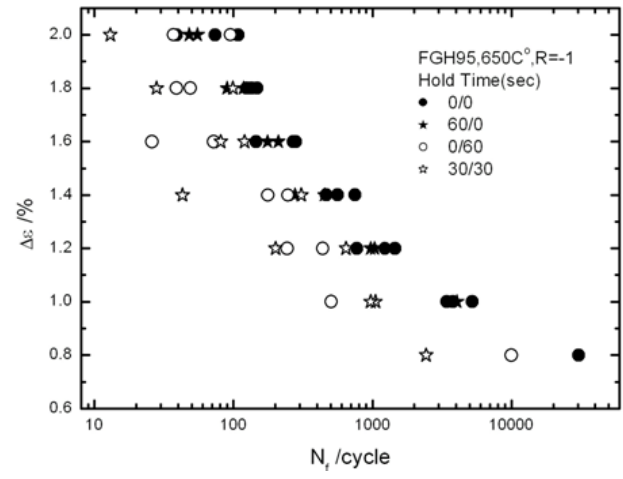

(a) FGH95

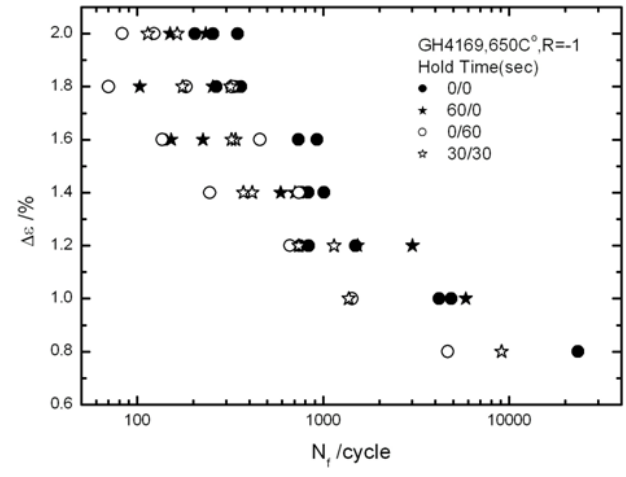

(b) GH4169

Fig. 1Total strain range as function of cycles to failure

According to the experimentaldata above, an energy-based HLC model is established as followed:

$$
N_{f}=A \cdot P_{t}^{n_{1}} \cdot P_{c}^{n_{2}} \cdot S_{t}^{n_{3}} \cdot S_{c}^{n_{4}}\left(\Delta \varepsilon_{i n} \Delta \sigma\right)^{n_{5}}
$$

Where $\Delta \varepsilon_{\text {in }}$ is inelastic strain range; $\Delta \sigma$ is stress range; $\Delta \sigma \Delta \varepsilon_{\text {in }}$ is inelastic hysteretic energy. The constants in the equation, which are $\mathrm{A}, \mathrm{n}_{1}, \mathrm{n}_{2}, \mathrm{n}_{3}, \mathrm{n}_{4}$ and $\mathrm{n}_{5}$, can be obtained by means of the non-linear least square method. Pt, Pc, St and Sc are the correction factors with the forms as followed: 


$$
\begin{aligned}
& P_{t}=e^{\sigma_{\max }} \quad P_{c}=e^{\sigma_{\min }} \\
& S_{t}=e^{\sigma_{\max } \cdot \Delta \varepsilon_{i n, t}} \quad S_{c}=e^{\sigma_{\min } \cdot \Delta \varepsilon_{i n, c}}
\end{aligned}
$$

Where $\sigma_{\max }$ and $\sigma_{\min }$ are maximal tensile and compressive stress at half life cycle respectively while $\Delta \varepsilon_{\mathrm{in}, \mathrm{t}}$ and $\Delta \varepsilon_{\mathrm{in,c}}$ are inelastic strain caused by tensile and compressive dwell at half life cycle respectively. So factors Pt and Pc play important roles in mean stress correction, while factors St and Sc are used in dwell correction to study the effect of additional energy (compared with no dwell) on fatigue. These factors are obtained from the hysteretic loop curve of each sample. The hysteretic loops at half life cycle of two samples are shown in Fig. 2. It is obvious that higher load would lead to larger inelastic strain energy and larger relaxed stress.

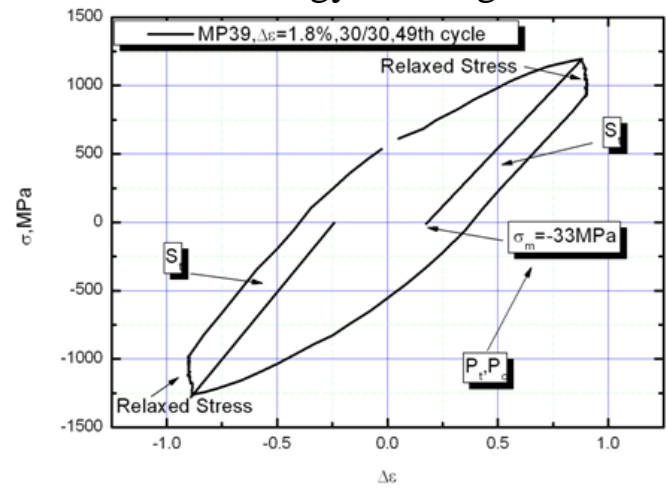

(a) No. MP39

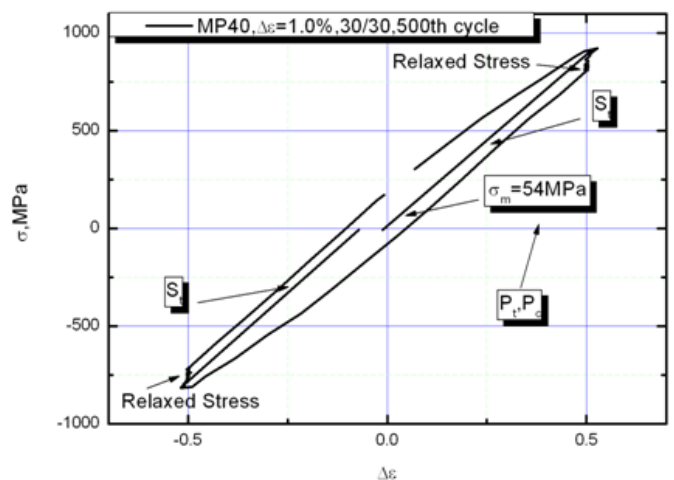

(b) No. MP40

Fig. 2 The hysteretic loops at half life cycle

The ability of the HLC model has been verified by the experiment data of FGH95 and GH4169. At the same time, the prediction accuracy of the model has been compared with that of the existing models by means of two parameters, which are the scatter band $\Delta \mathrm{S}$ and the standard deviation $\mathrm{SN}$, defined as followed:

$$
\begin{aligned}
& \Delta S=\max \left\{\frac{N_{\text {pre }}}{N_{\text {exp }}}\left(N_{\text {pre }}>N_{\text {exp }}\right), \frac{N_{\text {exp }}}{N_{\text {pre }}}\left(N_{p r e} \leq N_{\text {exp }}\right)\right\} \\
& S N=\left(\frac{\sum\left[\log \left(N_{p r e}\right)-\log \left(N_{\text {exp }}\right)\right]^{2}}{n}\right)^{1 / 2}
\end{aligned}
$$

Where $\mathrm{N}_{\text {pre }}$ is the predicted life; $\mathrm{N}_{\exp }$ is the observed life. Values of the parameters are listed in Table 2. In summary, the HLC model apparently leads to best results (the minimum scatter band and the standard deviation) while two worst results come from Manson-Coffin and total strain equation which didn't introduce the correction for fatigue-creep interaction. Frequency separation (FS), Ostergren, strain range partitioning (SRP), and strain energy partitioning (SEP) model were developed mainly for low-strength, high-ductility materials, such as GH4169. It is noteworthy that the HLC model can be extended from low-strength, high-ductility materials to high-strength low-ductility materials, such as FGH95. It is meaningful to enhance the applicability of HLC model. So an attempt is built to establish a general model in the developed form of HLC model in the paper which can be applied in high-cycle fatigue, thermal-mechanical fatigue, and multiaxial fatigue. 
Table 2 Evaluation of the life prediction models

\begin{tabular}{cccccc}
\hline & \multirow{2}{*}{ Prediction Model } & \multicolumn{2}{c}{ FGH95 } & \multicolumn{2}{c}{ GH4169 } \\
\cline { 2 - 6 } & $\Delta S$ & SN & $\Delta S$ & SN \\
\hline 1 & Manson-Coffin Equation & 14.6 & 0.3672 & 4.16 & 0.2610 \\
\hline 2 & Total Strain Equation & 14.7 & 0.3722 & 9.00 & 0.2857 \\
\hline 3 & Frequency-Separation Model & 3.76 & 0.2608 & 3.65 & 0.2171 \\
\hline 4 & Ostergren Model & 3.81 & 0.2767 & 4.07 & 0.2132 \\
\hline 5 & $\begin{array}{c}\text { Strainrange-Partitioning } \\
\text { Model }\end{array}$ & 3.94 & 0.2470 & 4.86 & 0.2248 \\
\hline 6 & $\begin{array}{c}\text { Strainenergy-Partitioning } \\
\text { Model }\end{array}$ & 3.45 & 0.2241 & 4.32 & 0.2321 \\
\hline 7 & Equation (1) (HLC Model) & 2.44 & 0.1568 & 3.00 & 0.2043 \\
\hline
\end{tabular}

\section{The GHLC model}

Based on the present form of HLC model, we can get:

$$
\Delta \varepsilon_{\text {in }} \Delta \sigma=a \cdot N_{f}^{b}, a=\left(\frac{1}{A \cdot P_{t}^{n_{1}} \cdot P_{c}^{n_{2}} \cdot S_{t}^{n_{3}} \cdot S_{c}^{n_{4}}}\right)^{\frac{1}{n_{5}}}, \quad b=\frac{1}{n_{5}}
$$

For high cycle fatigue, the inelastic energy should be replaced by the elastic energy as damage function, and the equation is written as:

$$
\Delta \varepsilon_{e} \Delta \sigma=c \cdot N_{f}^{d}, c=\left(\frac{1}{B \cdot P_{t}^{m_{1}} \cdot P_{c}^{m_{2}} \cdot S_{t}^{m_{3}} \cdot S_{c}^{m_{4}}}\right)^{\frac{1}{m_{5}}}, \quad d=\frac{1}{m_{5}}
$$

Then the generalized form of full strain energy is as followed:

$$
\Delta \varepsilon_{t} \Delta \sigma=\Delta \varepsilon_{i n} \Delta \sigma+\Delta \varepsilon_{e} \Delta \sigma=a \cdot N_{f}^{b}+c \cdot N_{f}^{d}
$$

Where coefficients a and $\mathrm{c}$ are not constants but variables for each data, which can correct the effect of mean stress, dwell time, and frequency, etc. The equation has a general form of strain energy which is similar to the total strain equation. For FGH95, it is interesting that the coefficients a and c are both linear function of lives in double logarithmic coordinates, see Fig. 3, while the data for GH4169 is not witnessed a linear relationship, see Fig. 4. Table 3shows a better prediction of FGH95 than that of GH4169 which indicates the GHLC model is also suitable for high-strength low-ductility materials like the original one. In addition, most calculated lives of FGH95 in Fig. 5 are correlated well in a band of \pm 2 except one long life data.

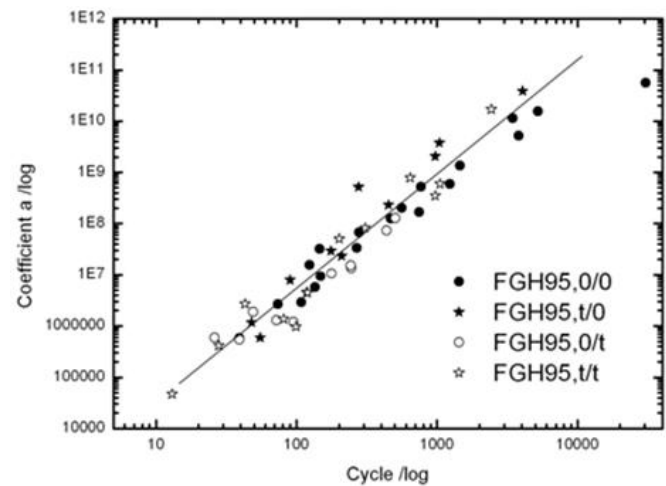

(a) Coefficient a

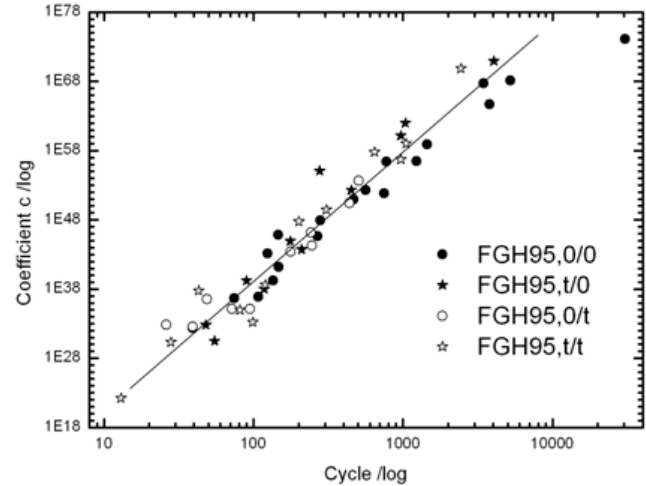

(b) Coefficient $\mathrm{c}$

Fig. 3 The coefficients a and $\mathrm{c}$ as function of cycles to failure 


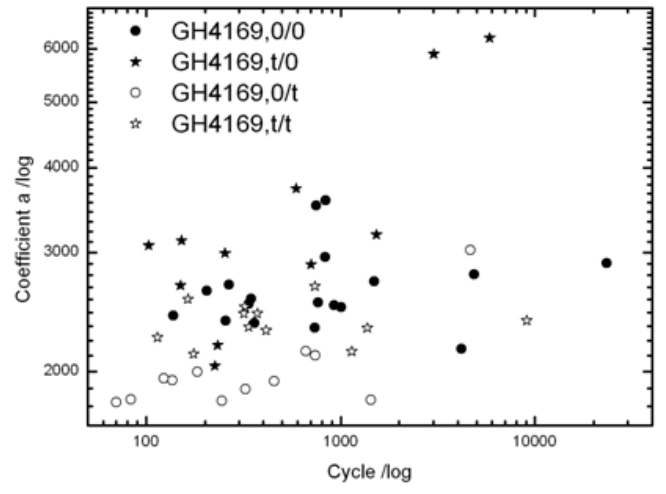

(a) Coefficient a

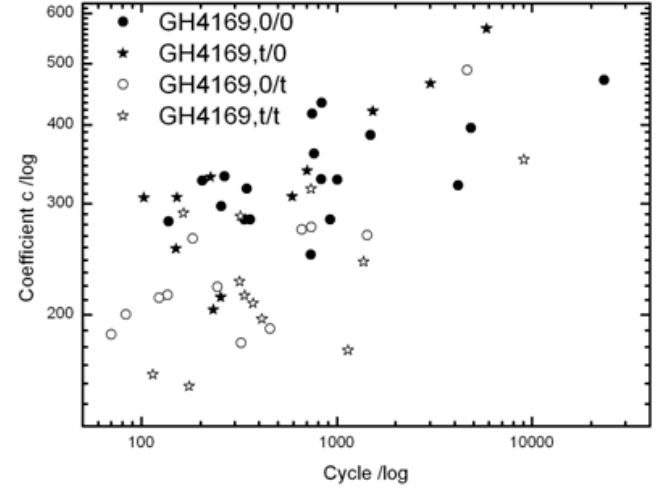

(b) Coefficient c

Fig. 4 The coefficients a and $\mathrm{c}$ as function of cycles to failure

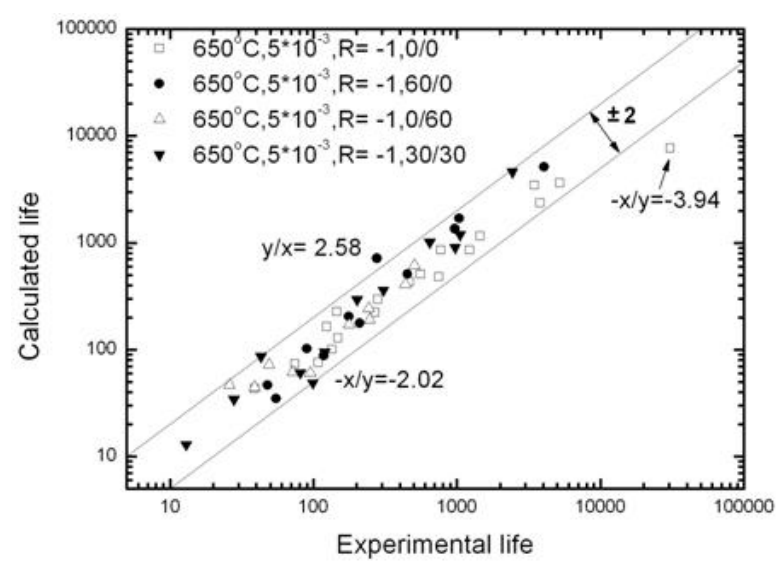

Fig. 5 Predicted lives of FGH95 by using the GHLC model

Table 3 Evaluation of the original model and evolved one

\begin{tabular}{cccccc}
\hline \multirow{2}{*}{ Prediction Model } & \multicolumn{2}{c}{ FGH95 } & \multicolumn{2}{c}{ GH4169 } \\
\cline { 2 - 6 } & Equation (6) & 2.44 & SN & $\Delta S$ & SN \\
\hline 1 & Equation (7) & 2.59 & 0.1568 & 3.00 & 0.2043 \\
\hline 2 & Equation (8) & 2.58 & 0.1672 & 6.03 & 0.3745 \\
\hline 3 & & &
\end{tabular}

\section{Application of the GHLC model}

\section{Used in high cycle fatigue}

The high cycle fatigue data of PM U720 [15] are used to check the validity of the GHLC model. Fig. 6 shows the lives predicted by the GHLC model and the stress-life equation with mean stress correction proposed by Morrow, respectively. The former gives a prediction with the scatter band of 3.98 and the standard deviation of 0.1847 , and the factors Pt and Pc become the most important factors while factors St and Sc degenerate to 1 due to lack of dwell. The latter gives a prediction with the scatter band of 4.32 and the standard deviation of 0.2035 . It is clear that the GHLC model leads to a better result. 


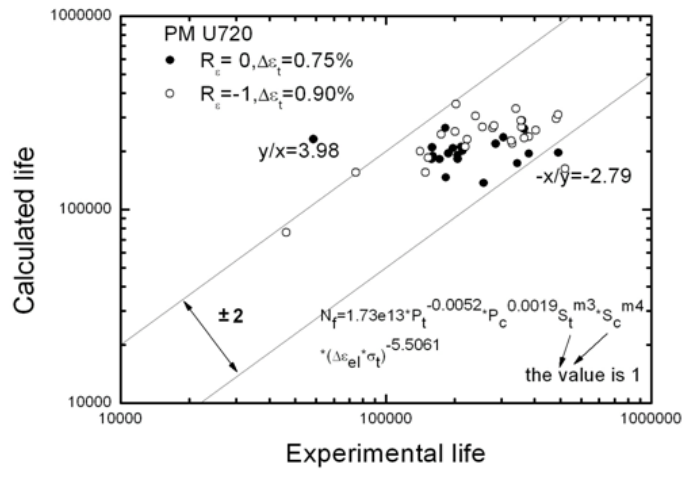

(a) GHLC model

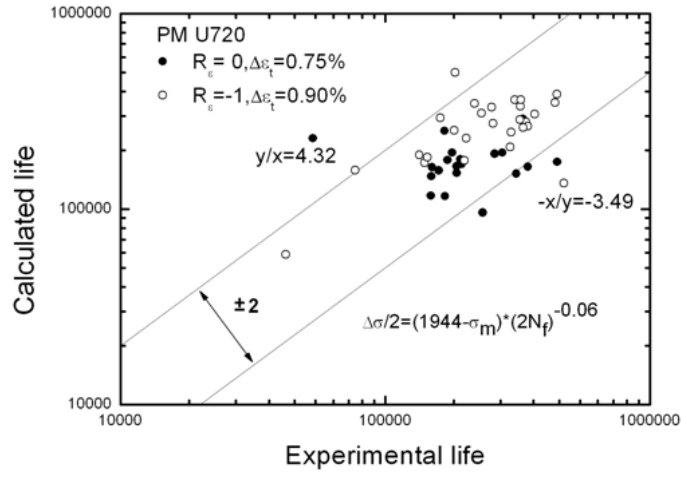

(b) stress- life equation modified by Morrow

Fig. 6 Predicted lives of PM U720

\section{Used in the rmal-mechanical fatigue}

The thermal-mechanical fatigue data of Inconel 718 [12] listed in Table 4 are used to check the validity of the developed model. Firstly, we use the isothermal data to establish the GHLC model of Inconel718 to obtain the values of the factors which are $A, n_{1}, n_{2}, n_{3}, n_{4}, n_{5}, B, m_{1}, m_{2}, m_{3}, m_{4}$, and $m_{5}$. Secondly, the model is used to predict the thermal-mechanical fatigue lives shown in Fig. 7. In order to correlate the experiment life better, a temperature correction factor is proposed as followed:

$$
P_{T}=e^{\left(\frac{1}{T_{1}}-\frac{1}{T_{2}}\right)}
$$

Where $T_{1}$ and $T_{2}$ are the maximal and minimal temperature in one thermal cycle, respectively. The temperature is determined to be $\mathrm{T}_{1}=\mathrm{T}_{\max }$ for in phase and $\mathrm{T}_{1}=\mathrm{T}_{\min }$ for out of phase. $\mathrm{P}_{\mathrm{T}}$ should equal to 1 when test operates under isothermal condition.

Basically it is still usable of $\Delta \sigma_{\text {in }} \Delta \varepsilon$ to express the inelastic strain energy, though the integral form of $\int \sigma \mathrm{d} \varepsilon$ would advise more precise value. The predicted lives ind icate that these data can be correlated well within a band of \pm 2 by introducing a temperature correction factor $\mathrm{P}_{\mathrm{T}}$ into the GHLC model.

Table 4 Tests of Inconel 718

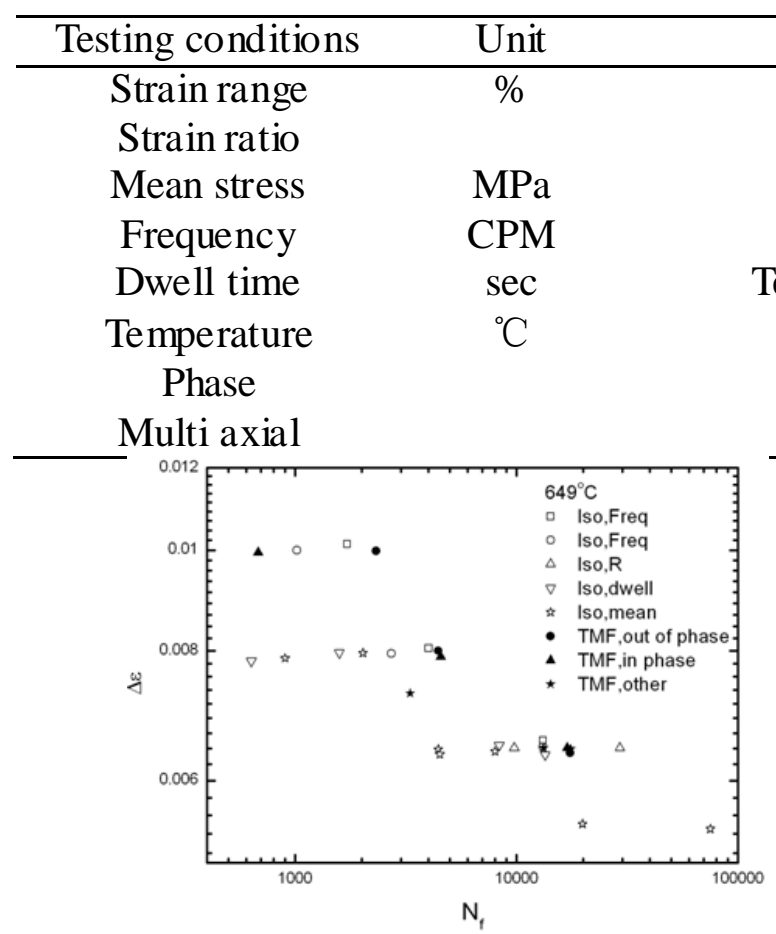

(a) Experiment lives

Value
$0.5 \sim 1.0$
$0,-1,-\infty$
$-300 \sim+300$
1,30

Tension 60, 65, 900; Compression 60, 900

$316,482,600,649,693,732$ IP, OP, CW, CCW

Fig. 7 Experiment lives and predicted ones of Inconel 718 


\section{Used in multiaxial fatigue}

The damage parameter $\Delta \sigma \Delta \varepsilon_{\text {in }}$ on the left side of Equation (3) is replaced by a parameter $\Delta \sigma \Delta \varepsilon_{\text {in }}+\Delta \tau \Delta \gamma_{\text {in }}$ on the critical plane to predict the multiaxial fatigue lives. Based on the data from the literature [12], predicted lives $\mathrm{N}_{\text {pre }}$ are given in Table 5. It indicates that most of the calculated values are not conservative within a band of 10 though it is viable that the HLC model can be used in multiaxial fatigue. However, there should be more suitable damage parameters to choose.

Table 5 Multiaxial fatigue data of Inconel $718\left(649^{\circ} \mathrm{C}\right)$

\begin{tabular}{cccccccc}
\hline No. & $\Delta \varepsilon_{\text {in }}, \%$ & $\Delta \gamma_{\text {in }}, \%$ & $\Delta \sigma, \mathrm{MPa}$ & $\Delta \tau, \mathrm{MPa}$ & $\mathrm{N}_{\exp }$ & $\mathrm{N}_{\text {pre }}$ & $\Delta \mathrm{S}$ \\
\hline 308 & 0.0971 & 0.1603 & 828.4 & 447.6 & 5800 & 9551 & 1.64 \\
306 & 0.0743 & 0.1297 & 834.4 & 452.0 & 2470 & 11138 & 4.50 \\
309 & 0.0025 & 0.0083 & 759.3 & 223.0 & 21274 & 177956 & 8.36 \\
313 & 0.0905 & 0.0454 & 937.1 & 273.8 & 10150 & 7500 & -1.35 \\
311 & 0.0243 & 0.0056 & 924.2 & 275.1 & 6367 & 30125 & 4.73 \\
314 & 0.0023 & 0.0440 & 761.0 & 217.4 & 31000 & 121188 & 3.90 \\
312 & 0.0194 & 0.0103 & 923.1 & 280.6 & 12480 & 26896 & 2.15 \\
315 & 0.0218 & 0.0142 & 933.2 & 268.4 & 7500 & 25712 & 3.42 \\
\hline
\end{tabular}

\section{Life pre diction of PM turbine disc}

The life models for materials should be of usage in life evaluation of structure, which is an engineering research objective. We have already used the GHLC model in PM FGH95 alloy, and then the model should be validated to be used in life prediction of PM turbine disc manufactured by PM FGH95 alloy, which is an important component in hot section of aero engine.

A FE model of PM disc is established to obtain the distribution of stresses. Then three check positions with high stresses are confirmed, which locate at the center of disc, the tenon, and the fillet, named position 1, 2, and 3, respectively, see Fig. 8.

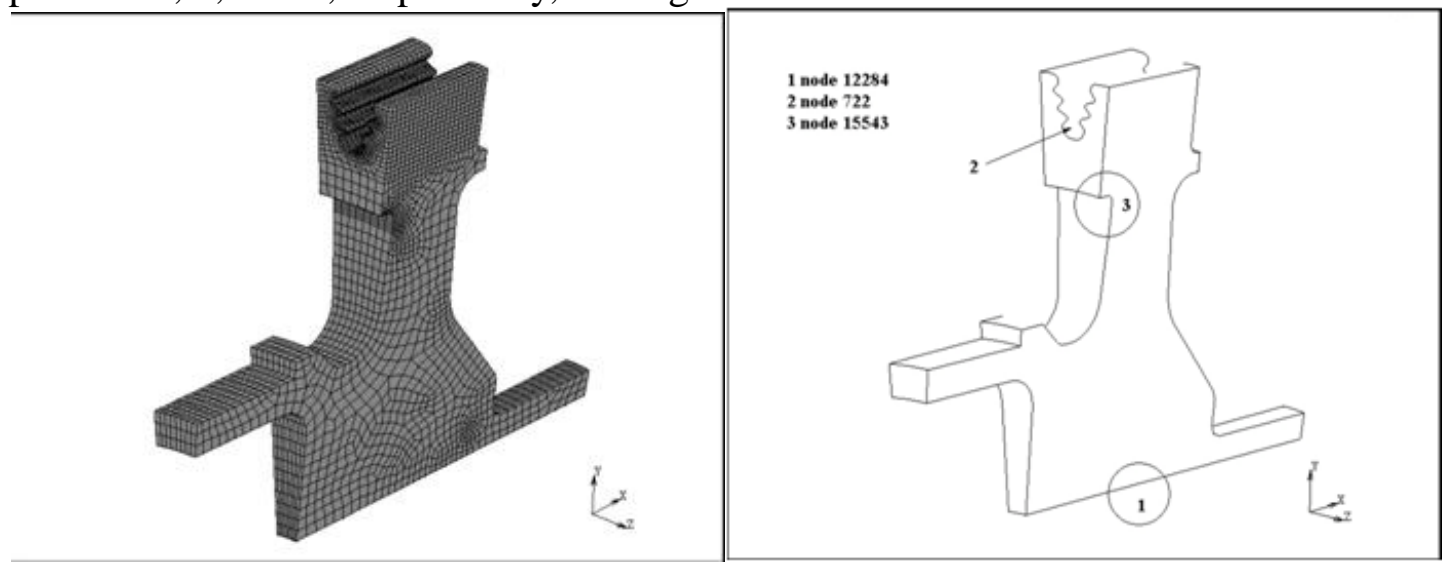

(a) FE model

(b) Check positions

Fig. 8 The FE model and check positions of the PM disc

Both the GHLC model and the linear damage accumulation model are used in life prediction to verify the results of each other. One working cycle of the disc is a trapezium waveform with hold-time of one hour, so the total damage D of one cycle can be written as

$$
D=D_{f}+D_{c}=\frac{1}{N_{f}}+\frac{t_{c}}{T_{c}}
$$

Where $D_{f}$ and $D_{c}$ are the fatigue damage and the creep damage, $t_{c}$ is the hold-time, and $T_{c}$ is the material rupture time under invariable stress leave at evaluated temperature which is a function of load and temperature. We have performed the creep tests at $650^{\circ} \mathrm{C}$ under axial stress control, see Fig. 9 , then interpolation is used to get the value of $\mathrm{T}_{\mathrm{c}}$ at the check position. 


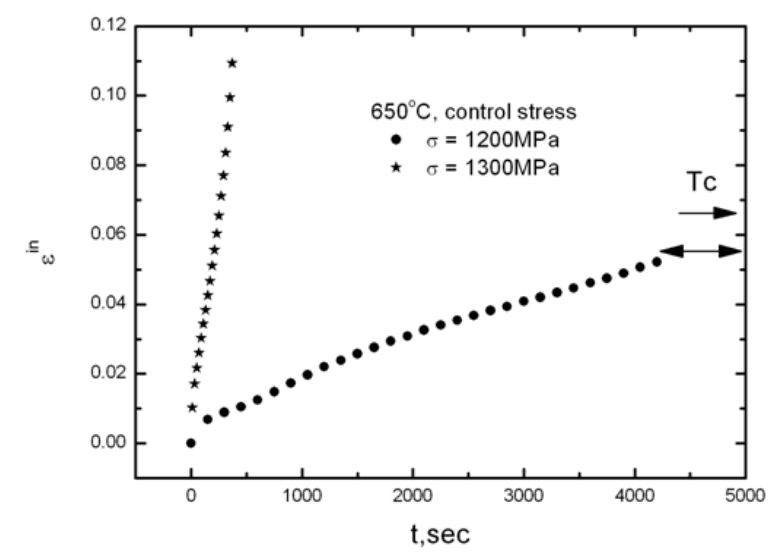

Fig.9 Creep curves of FGH95

The equivalent stress and the principle stress are selected as the damage parameters to evaluate the life of the disc, the results are listed in Table 6 and Table 7. For position 1, calculated lives of two methods have the same magnitude of $10^{5}$, and both are close to the design life of the disc. For position 2 , there is an obvious difference between the two results, and the GHLC model would give a non-conservative value. High temperature and long hold-time result in distinct creep damage at position 2. It indicates that there is potential risk in using GHLC model to evaluate the creep damage raised by the bad relativity between test loading and real working condition. The disk operates under working conditions of low stress and long hold-time, but the test is always performed under high stress short hold-time condition.

Table 6 Calculated lives by the GHLC model

\begin{tabular}{|c|c|c|c|c|}
\hline \multicolumn{2}{|c|}{ Damage parameters } & $\begin{array}{c}\text { Position } 1 \\
\text { Node } 12284\end{array}$ & $\begin{array}{l}\text { Position } 2 \\
\text { Node } 722\end{array}$ & $\begin{array}{c}\text { Position } 3 \\
\text { Node } 15543\end{array}$ \\
\hline \multirow{6}{*}{$\begin{array}{c}\text { Damage } \\
\text { parameters } \\
\text { coming } \\
\text { from } \\
\text { equivalent } \\
\text { stress-strain } \\
\text { cycle curve }\end{array}$} & Max. equivalent stress /MPa & 1026.2 & 934.7 & 798.5 \\
\hline & Min. equivalent stress /MPa & 49.0 & 167.0 & 131.3 \\
\hline & Max. equivalent strain $/ 10^{-2}$ & 0.412 & 0.397 & 0.365 \\
\hline & Min. equivalent stress $/ 10^{-2}$ & 0.021 & 0.060 & 0.019 \\
\hline & Inelastic strain $/ 10^{-2}$ & $<0.0001$ & $<0.0001$ & $<0.0001$ \\
\hline & Fatigue life /cycle & $7.80 \times 10^{5}$ & $8.95 \times 10^{5}$ & $9.31 \times 10^{5}$ \\
\hline \multirow{6}{*}{$\begin{array}{l}\text { Damage } \\
\text { parameters } \\
\text { coming } \\
\text { from } \\
\text { principle } \\
\text { stress-strain } \\
\text { cycle curve }\end{array}$} & Max. principle stress /MPa & 973.0 & 1199.0 & 1154.8 \\
\hline & Min. principle stress /MPa & 47.8 & 239.0 & 93.8 \\
\hline & Max. principle strain $/ 10^{-2}$ & 0.453 & 0.471 & 0.388 \\
\hline & Min. principle strain $/ 10^{-2}$ & 0.039 & 0.086 & 0.076 \\
\hline & Inelastic strain $/ 10^{-2}$ & $<0.0001$ & $<0.0001$ & $<0.0001$ \\
\hline & Fatigue life /cycle & $7.80 \times 10^{5}$ & $7.89 \times 10^{5}$ & $8.21 \times 10^{5}$ \\
\hline
\end{tabular}

Table 7 Calculated lives by the linear damage accumulation model

\begin{tabular}{cccc}
\hline Location, Node & Position 1,12284 & Position 2,722 & Position 3, 15543 \\
\hline Loading & $426.3^{\circ} \mathrm{C}, 1026.2 \mathrm{MPa}$ & $599.6^{\circ} \mathrm{C}, 934.7 \mathrm{MPa}$ & $469.2^{\circ} \mathrm{C}, 798.5 \mathrm{MPa}$ \\
\hline$T_{c}$, hour & $3.53 \times 10^{9}$ & $1.30 \times 10^{3}$ & $4.20 \times 10^{9}$ \\
\hline Creep damage, $D_{c}$ & $4.25 \times 10^{-10}$ & $1.15 \times 10^{-4}$ & $3.57 \times 10^{-10}$ \\
\hline Fatigue damage, $D_{f}$ & $5.68 \times 10^{-6}$ & $5.05 \times 10^{-7}$ & $1.04 \times 10^{-8}$ \\
\hline$N=1 /\left(D_{f}+D_{c}\right)$ & $1.76 \times 10^{5}$ & $8.65 \times 10^{3}$ & $9.29 \times 10^{7}$ \\
\hline
\end{tabular}

\section{Conclusions}

This paper focuses on establishing a general life model which can be applied in high cycle fatigue, 
thermal-mechanical fatigue, multiaxial fatigue and structural fatigue. The following conclusions are drawn:

1. Compared with other existing life models, the GHLC model is suitable for high-strength and low-ductility materials, such as PM alloys, which would give a more accurate predicted value.

2. Testing conditions shown in Fig. 10, such as temperature, frequency, waveform, hold-time, and strain ratio, would have two key effects on the fatigue of materials. One changes the shape of hysteretic loops which is modified by factors St and Sc in GHLC model; the other changes the position of hysteretic loops which is modified by factors Pt and Pc in the model.

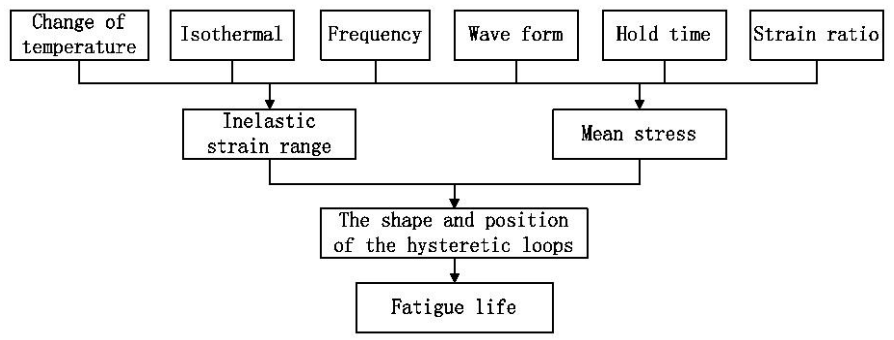

Fig. 10 Influential factors of material life

3. The HLC model and its evolved form can be used in life prediction of the engineering structure, but the parameters of the model coming from materials test are usually not suitable for the structure subjected to the work loading. Life prediction of structure is always a difficulty and a concern in any cases, and there are still some uncertain factors affecting the structure lives.

\section{Acknowledge ments}

This work is supported by the project AR026 from Chinese Aeronautical Establishment Shanghai Branch and the National Natural Science Foundation of China with No.51105023 and No.51475024.

\section{References}

[1] Manson S.S. Behavior of Materials under Conditions of Thermal Stress. Heat Transfer Symposium. University of Michigan Engineering Research Institute, 1953:9-75

[2] Coffin L.F. A study of the Effects of Cyclic Thermal Stresses on a Ductile Metal. Trans. ASME, $1954,76: 931-950$

[3] Coffin L.F. The Effect of Frequency on High Temperature Low-Cycle Fatigue. AFFDL-TR-70-144, 1970:301-311

[4 ]Coffin L.F. The Concept of Frequency Separation in Life Prediction for Time-Dependent Fatigue. In ASME-MPC Symposium on Creep-Fatigue Interaction, 1976:349-363

[5] Majumdar S., Maiya P. S. A Damage Equation for Creep-Fatigue Interaction. In ASME-MPC Symposium on Creep-Fatigue Interaction. 1976:323-336

[6] Manson S.S. Creep-Fatigue Analysis by Strainrange Partitioning. NAS A-TM-X-67823, 1971

[7] Halford G. R., Saltsman J. F. Strainrange Partitioning: A Total Strain Range Version. NASA-TM-83023, 1983

[8] Ostergren W.J. A Damage Function and Associated Failure Equations for Predicting Hold Time and Frequency Effects in Elevated Temperature Low-Cycle Fatigue. Journal of Testing and Evaluation, 1976, 4(5):327-339

[9]Jin-rui He, Zuo-xiang Duo, You-lian Ning, etc. Application of Strainenergy-Partitioning Model in GH33 A and 1Cr18Ni9Ti. The 1st Conference of High temperature fatigue, 1982 
[10] Yong-lian Wang. A generalized frequency modified damage function model for high temperature low cycle fatigue life prediction. International Journal of fatigue, 1997, 19(4):345-350

[11] Miner M. A. Cumulative damage in fatigue. Journal of Applied Mechanics, 1945, 12:159-164

[12] Nelson R. S., Levan G. W., Harvey P. R. Creep Fatigue Life Prediction for Engine Hot Section Materials (Isotropic) Final Report. NASA-CR-189221, N93-18578, 1993

[13] Chaboche J. L. An overview of the damage approach of durability modeling at elevated temperature. Fatigue Fract. Engng. Mater. Struct, 1996, 24:405-418

[14] Da-Sheng Wei, Xiao-Guang Yang. Investigation and Modeling of Low Cycle Fatigue Behaviors of Two Ni-Based Superalloys under Dwell Conditions. International Journal of Pressure Vessels and Piping, 2009, 86:616-621

[15] Gabb T. P., Bonacuse P. J., Ghosn L. J. Assessments of Low Cycle Fatigue Behavior of Powder Metallurgy Alloy U720. Fatigue and Fracture Mechanics, 2000, 31:110-127 